\title{
The diagnostic importance of invasive micropapillary carcinoma in the canine mammary gland: clinicopathological, immunohistochemical and survival analysis
}

\author{
Conrado O Gamba ${ }^{1}$, Éverton J Dias ${ }^{1}$, Lorena GR Ribeiro², Liliane C Campos ${ }^{1}$, Alessandra Estrela-Lima², \\ Enio Ferreira', Geovanni D Cassali ${ }^{1 *}$
}

From São Paulo Advanced School of Comparative Oncology

Águas de São Pedro, Brazil. 30 September - 6 October 2012

\section{Background}

Invasive micropapillary carcinoma (IMPC) of the mammary gland, despite its rare occurrence in humans and dogs, is an important neoplasm due to its aggressive behaviour. Our aim was to evaluate clinicopathological and immunophenotypical characteristics of IMPC and to determine overall survival of dogs with this tumour.

\section{Materials and methods}

Twenty-two IMPC cases were selected for survival and clinicopathological analysis. Immunohistochemistry was performed for Epidermal Growth Factor Receptor (HER)-2, Epidermal Growth factor Receptor (EGFR), Oestrogen Receptor (ER), Progesterone Receptor (PR), CD-31, Cytokeratin (CK) AE1AE3, p63 and Epithelial Membrane Antigen (EMA).

\section{Results}

Of the 22 studied cases, the majority had $>3 \mathrm{~cm}$ neoplasms $(15 / 19,78.95 \%)$ and lymph node metastases $(16 / 16,100 \%)$, but only two cases $(2 / 9,22.2 \%)$ had distant metastases. The IMPCs were classified as either pure $(15 / 22,68.18 \%)$ or mixed $(7 / 22,31.82 \%)$ types. A predominance of moderate histological grade (16 grade II) tumours was observed and the average overall survival was 120 days. Positive immunohistochemical staining for EMA and negative staining for CD-31, p63 and CK AE1AE3 in cystic formations confirmed the micropapillary nature of these neoplasms. The majority of cases were positive for RE (19/20,95\%) and RP (19/20, 95\%), but lacked HER-2 (16/ $22,72.72 \%)$ and EGFR $(15 / 22,68.18 \%)$ over-expression.

\section{Conclusions}

These findings demonstrate that, similar to the situation pertaining with human IMPCs, canine IMPCs behave aggressively with high rates of metastasis to regional lymph nodes and short overall survival times.

\section{Financial support \\ FAPEMIG, CAPES and CNPq.}

\section{Author details \\ 'Department of General Pathology, Institute of Biological Sciences, Federal University of Minas Gerais, Belo Horizonte, Minas Gerais, Brazil. ${ }^{2}$ Department of Pathology and Clinics, School of Veterinary Medicine, Federal University of Bahia, Salvador, Bahia, Brazil.}

Published: 4 April 2013

doi:10.1186/1753-6561-7-S2-P17

Cite this article as: Gamba et al:: The diagnostic importance of invasive micropapillary carcinoma in the canine mammary gland:

clinicopathological, immunohistochemical and survival analysis. BMC Proceedings 2013 7(Suppl 2):P17.

\footnotetext{
* Correspondence: cassalig@icb.ufmg.br

'Department of General Pathology, Institute of Biological Sciences, Federal

University of Minas Gerais, Belo Horizonte, Minas Gerais, Brazil

Full list of author information is available at the end of the article
}

(c) 2013 Gamba et al; licensee BioMed Central Ltd. This is an Open Access article distributed under the terms of the Creative Commons 